\title{
Improvement of the Bioavailability and Glycaemic Metabolism of Cinnamon Oil in Rats by Liquid Loadable Tablets
}

\author{
Chunchao Han ${ }^{1}$ and Bo Cui ${ }^{2}$ \\ ${ }^{1}$ School of Pharmacy, Shandong University of Traditional Chinese Medicine, Jinan 250355, China \\ ${ }^{2}$ College of Food and Biological Engineering, Shandong Polytechnic University, Jinan 250353, China
}

Correspondence should be addressed to Bo Cui, chunchaoh@126.com

Received 24 October 2011; Accepted 12 December 2011

Academic Editor: Javed Ali

Copyright ( $) 2012$ C. Han and B. Cui. This is an open access article distributed under the Creative Commons Attribution License, which permits unrestricted use, distribution, and reproduction in any medium, provided the original work is properly cited.

\begin{abstract}
The purpose of this study is to investigate the bioavailability and glycaemic metabolism of cinnamon oil (CIO) carried by liquidloadable tablets (CIO-LLTs), the carrier of a CIO self-emulsifying formulation (CIO-LS). The results of tests performed to evaluate the physical properties of the CIO-LLT complied with Chinese Pharmacopeia (2010). The release profile suggested that the CIOLLT preserved the enhancement of in vitro dissolution of cio. After orally administration, the plasma concentration-time profile and pharmacokinetic parameters suggested that a significant increase $(P<0.0001)$ in the $C_{\max }$, AUC and $F$ were observed in the CIO-LLT. The blood glucose and the HbAlc were significantly decreased in alloxan-induced hyperglycemic rats $(P<0.05$, $P<0.01$, resp.), while the level of insulin secretion was markedly elevated in alloxan-induced hyperglycemic rats $(P<0.05)$. The alloxan-damaged pancreatic $\beta$-cells of the rats were partly recovered gradually after the rats were administered with CIO-LLT 45 days later. CIO-LLT could improve the bioavailability and glycaemic metabolism of CIO.
\end{abstract}

\section{Introduction}

According to the World Health Organization, it is estimated that approximately 150 million people worldwide have diabetes mellitus at present [1]. Therefore, new therapeutic approaches are needed to treat diabetes more efficiently. Presently, there is growing interest in herbal remedies due to the side effects associated with the oral hypoglycemic agents for the treatment of diabetes mellitus [2]. The plant kingdom is a wide field to search for natural effective oral hypoglycemic or hypolipidemic agent that has slight or no side effects. More than 400 plants with glucose lowering effect are known [3]. They might be used in various forms like food and medicines, which contain both organic and inorganic constituents.

Cinnamon is one of the well-known and oldest spices, which has been used for centuries in several cultures [4]. It has been traditionally used in Ayurvedic and Chinese medicine as a treatment for diabetes [5]. Research has shown that cinnamon oil (CIO) is particularly very helpful for patients suffering from type 2 diabetes. However, the poor watersoluble drug, cinnamon oil, leads to poor dissolution and bioavailability. To overcome these problems, various formulation strategies such as cyclodextrin, surfactants, nanoparticles, lipids carriers, and solid dispersions are reported [6]. In recent years, much attention has been focused on selfemulsifying drug delivery systems (SEDDSs), which are isotropic mixtures of oil, surfactant, cosurfactant, and drug that form fine oil-in-water emulsion when introduced into aqueous medium under gentle agitation [7-9]. SEDDSs have shown a reasonable success in improving oral bioavailability of poorly water soluble drugs $[10,11]$.

However, SEDDSs are usually formulated in a liquid form which has some disadvantages such as high production costs, low drug incompatibility, and poor physical and chemical stability. The incorporation of the self-emulsifying mixture into a solid dosage form is desirable as it combines the advantages of SEDDS (high solubility and bioavailability) with those of solid dosage forms (high stability). The transformation of liquid lipid systems into a solid oral dosage form has been attempted by several methods such as capsule filling, spray drying, adsorption onto solid carriers, and melt granulation as well as other techniques [12-15]. The tablet is the most popular dosage form in use today. It is simple and 
convenient to use. Liquid-loadable tablets (LLTs), prepared by direct compression of solid carrier particles and subsequently loading the liquid into the tablet, have a higher liquid loading [16]. The work presented in this paper focuses on the pharmacokinetic (PK) performance of CIO from loaded LLT and the effects of CIO-loadable tablets (CIO-LLT) on glycaemic metabolism.

\section{Materials and Methods}

2.1. Animals. Healthy male adult Wistar rats (2 months old and weighing $225 \pm 25 \mathrm{~g}$ ) were used in the study. The study was approved by Shandong University's ethics committee, and all procedures complied with the guidance set out in the Guidelines for Caring for Experimental Animals published by the Ministry of Science and Technology of China. Every care was taken to minimize discomfort, distress, and pain.

2.2. Materials. Cinnamon oil was obtained from Shanghai Yansheng biotechnology Co., Ltd. China. Magnesium aluminometasilicate (MAS) was obtained from Jinan Kailida Chemical Technology Co., Ltd China.

2.3. Preparation of CIO-Loaded SEDDS (CIO-LS). Based on the pilot studies, the blank SEDDSs were prepared by mixing of 30\% Miglyol 812 (oil), 60\% Cremophor RH40 and Tween 80 (surfactant, $2: 1$ ), and $10 \%$ Transcutol P (cosurfactant) at $50^{\circ} \mathrm{C}$ with a magnetic stirrer. Then $\mathrm{CIO}$ and Aerosil 200 $(1000 \mathrm{mg})$ suspended in $150 \mathrm{~mL}$ ethanol were dissolved in the blank SEDDS with stirring until forming an isotropic mixture. The mixture was then kept at room temperature and equilibrating for $24 \mathrm{~h}$.

2.4. Reconstitution Properties of the SEDDS. The emulsification time of the SEDDS formulations was evaluated according to the way described in detail by $\mathrm{Xi}$ et al. [17]. In brief, SEDDS $(250 \mu \mathrm{L})$ was introduced into $500 \mathrm{~mL}$ of distilled water at $37^{\circ} \mathrm{C}$ under gentle agitation by a standard stainless steel dissolution paddle rotating at $50 \mathrm{rpm}$. The emulsification time was assessed visually. All experiments were carried out in triplicates.

Droplet size was determined by Zetasizer Nano ZS (Jinan Runzhi Instruments, China) with dynamic light scattering particle size analyzer at a wavelength of $635 \mathrm{~nm}$ and at a scattering angle of $90^{\circ}$ at $25^{\circ} \mathrm{C}$. All studies were repeated three times, and the values of $z$-average diameters were used. The $z$-average diameter, also referred to as the harmonic intensity-weighted average hydrodynamic diameter, of the emulsions was derived from cumulated analysis by the Automeasure software. Zeta potential of the emulsion formed after addition of SEDDS into $0.1 \mathrm{~N} \mathrm{HCl}$ solution was measured using Zetasizer Nano ZS.

2.5. Preparation of LLT. The composition of LLT was MAS/ magnesium stearate $(99.5: 0.5 \mathrm{w} / \mathrm{w} \%)$ [16]. The additive was required during the tabletting process to avoid undesired adhesion of MAS powder to the tablet punches when under compression. Tablets of approximately $250 \mathrm{mg}$ were compressed using a round $12 \mathrm{~mm}$ flat-faced punch. Tablet hardness was determined using a hardness tester. Tablet disintegration was performed in $0.1 \mathrm{~N} \mathrm{HCl}$ using an automatic disintegration tester (JB-1, Tianjian Xinzhou, China) according to the conditions of the Chinese Pharmacopoeia (2010) for uncoated tablets.

2.6. Loading of CIO in to Tablet. Tablets were placed in excess of CIO-SEDDS and allowed to absorb the liquid until a constant tablet weight was reached. Before weighing, excess of liquid on the surface of the tablets was removed by tissue paper. After few hours of storage, the tablet surface is dry, comparable to the nonloaded tablet [18].

2.7. Characterization of CIO-Loaded Tablet (CIO-LLT). Tablets were evaluated by performing quality control tests for uniformity of drug content, friability, disintegration, hardness, and weight variation. All tests were carried out in triplicates and according to Chinese Pharmacopoeia (2010).

2.8. In Vitro Drug Release Study. CIO-LS and CIO-LLT were tested in vitro in $950 \mathrm{~mL}$ purified water at $37^{\circ} \mathrm{C}$ using rotating basket apparatus (Chinese Pharmacopoeia) at a rotation speed of $100 \mathrm{rpm}$. Samples were withdrawn at predetermined time intervals and then mixed with $150 \mu \mathrm{L}$ of methanol containing $1.75 \mu \mathrm{g}$ of $\alpha$-naphthoflavone. The resultant solution was filtered, and an aliquot $(100 \mu \mathrm{L})$ of the filtrate was subjected to HPLC analysis.

2.9. In Vivo Protocols. Wistar rats were divided randomly into four groups (six animals in each group). The first group (CIO) was treated orally $(100 \mathrm{mg} / \mathrm{kg}$ ) CIO formulated in normal saline containing 3\% Tween 80. Group II (CIO-LS) and group III (CIO-LLT) were treated orally CIO-SEDDS $(100 \mathrm{mg} \mathrm{CIO} / \mathrm{kg}$ ) and CIO-LLT $(100 \mathrm{mg} \mathrm{CIO} / \mathrm{kg}$ ), respectively. Group IV was treated (i.v.) CIO sample $(100 \mathrm{mg} / \mathrm{kg}$ ) used as control group. Before dosing, the rats were fasted overnight. Food was given minimum $2 \mathrm{~h}$ after dosing. A $3 \mathrm{~mL}$ blood samples were drawn from the tail vein before dosing and at the following times: $15 \mathrm{~min}, 30 \mathrm{~min}, 45 \mathrm{~min}$, $1 \mathrm{~h}, 1.5 \mathrm{~h}, 3 \mathrm{~h}, 4 \mathrm{~h}, 6 \mathrm{~h}$, and $24 \mathrm{~h}$ after dosing. Blood samples were centrifuged at $3000 \mathrm{~g}$ for $10 \mathrm{~min}$, and plasma samples were harvested. Each plasma sample $(100 \mu \mathrm{L})$ was mixed with $200 \mu \mathrm{L}$ of Methanol, vortexed, and centrifuged at 16,000 $\mathrm{g}$ for $5 \mathrm{~min}$. The supernatant was filtered with a $0.45-\mu \mathrm{m}$ syringe filter, and $100 \mu \mathrm{L}$ of the filtrate was subjected to HPLC analysis.

2.10. Pharmacokinetic Parameter Analyses. Pharmacokinetic parameters were calculated from the corresponding plasma concentration-time curves using noncompartmental analysis (WinNonlin 4.0, Pharsight, Mountain View, CA, USA). The area under the plasma concentration-time curve from time 0 to time infinity $\left(\mathrm{AUC}_{0-\infty}\right), C_{\max }, T_{\max }$ were determined from the concentration-time profile. The absolute bioavailability $(F)$ was calculated using the following equations:

$$
F=\frac{\left(\mathrm{AUC}_{\text {oral/i.p. }} * \text { Dose }_{\text {i.v. }}\right)}{\left(\mathrm{AUC}_{\text {i.v. }} * \text { Dose }_{\text {oral/i.p. }}\right)} .
$$


2.11. Estimation of CIO-LLT on Glycaemic Metabolism. Animals were fasted for $12 \mathrm{~h}$ and were then injected (i.v.) with alloxan $(75 \mathrm{mg} / \mathrm{kg})$ solution that was made with saline. Fortyeight hours later, blood samples were collected from the tail veins of the rats. The blood glucose was analyzed with a Glucometer-4 (Bayer). The blood glucose level of rats greater than $11.1 \mathrm{mmol} / \mathrm{L}$ was selected as hyperglycemic rats.

Forty hyperglycemic rats were selected and randomly divided into 4 groups. The first group (CIO) was treated orally $(100 \mathrm{mg} / \mathrm{kg})$ CIO formulated in normal saline containing 3\% Tween 80. Group II (CIO-LS) and group III (CIO-LLT) were treated orally CIO-SEDDS (100 mg CIO/kg) and CIO-LLT (100 mg CIO/kg), respectively. Group IV was treated orally saline used as control group. On the 45th day, blood samples were collected from the orbital veins to measure the to determine the blood glucose levels and HbA1c with the HbAlc Apparatus (Variant II, Bio-Rad Laboratories) and insulin with an enzyme-linked immunosorbant assay (ELISA) kit (Shanghai Jinma Biological Technology, Inc., China), respectively. Then, the rats were sacrificed. The pancreas was dissected out and placed in 10\% buffered formalin and the liver was dissected out for the measurement of hepatic glycogen.

2.12. Data Analysis. The data are expressed as mean \pm SEM. Statistical significance was tested by two-tailed Student's $t$ test for differences between two groups and by one-way ANOVA carried out using the SAS statistical package (version 8.1, SAS Institute, Cary, NC, USA) for testing differences between means for more than two groups. Statistical significance level was set at $P<0.05$.

\section{Results and Discussion}

The work presented in this paper focuses on the ability of LLT prepared from MAS to be loaded with a SEDDS system containing $\mathrm{CIO}$, the pharmacokinetic (PK) performance of CIO from loaded LLT and the effects of CIO-loadable tablets (CIO-LLT) on glycaemic metabolism. MAS is nontoxic and consists of highly porous spherical particles with a median size of $110 \mu \mathrm{m}$ and a specific surface area of approximately $370-420 \mathrm{~m}^{2} / \mathrm{g}$ [16]. Due to its excellent fluidity and compressibility, MAS can be mechanically compacted into stable tablets. The mechanical stability of the unloaded LLT was $29 \mathrm{~N} \pm 8 \%(n=10)$. Disintegration time of the unloaded LLT was $0.27 \pm 0.11 \mathrm{~min}$. It was the time taken by each of the 6 tablets to pass completely through the 10 mesh screen.

3.1. Reconstitution Properties of the SEDDS. SEDDS formulation disperse quickly and completely when subjected to aqueous environment under mild agitation. The efficiency of self-emulsification can be estimated by measuring the rate of emulsification and the droplet size distribution [19]. As shown in Table 1, emulsification time was $23 \mathrm{~s}$ for SEDDS. It is much related to their hydrophilic-lipophilic balance (HLB) value of surfactant and cosurfactant.

It has been reported that any change in interfacial film influences the surface curvature of the droplet leading to differences in the droplet size [20-22]. As shown in Table 1,
TABLE 1: Reconstitution properties of the SEDDS.

\begin{tabular}{lc}
\hline & SEDDS \\
\hline Emulsification time (seconds) & $23 \pm 3$ \\
Zeta potential & $+2.00 \pm 0.30$ \\
Droplet size (nm) & 132.5 \\
Polydispersity index (PDI) & $0.160 \pm 0.020$ \\
\hline
\end{tabular}

Values are shown as means \pm SD.

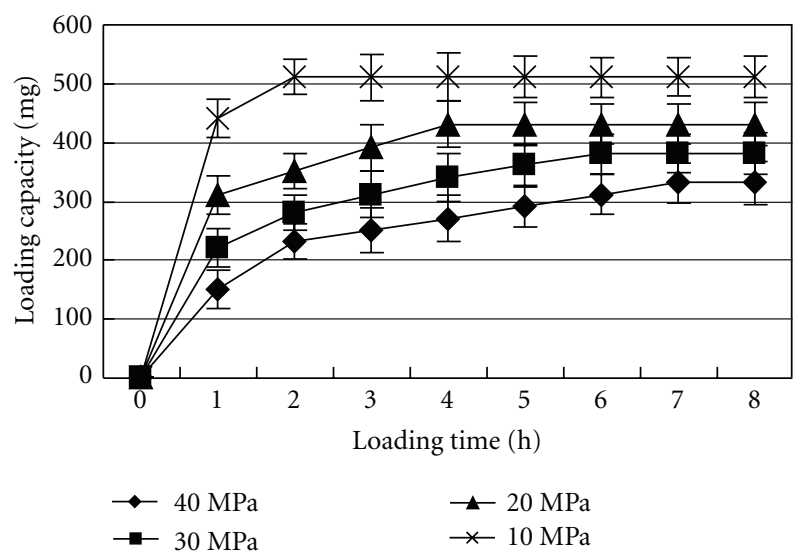

FIgURE 1: Correlation between SEDDS loading and loading time.

the $z$-average droplet sizes for SEDDS system was $132.5 \mathrm{~nm}$. The mean droplet size and size distribution (polydispersity index) was 0.160 . SEDDS showed a zeta potential of $+2.00 \mathrm{mV}$, therefore providing prolonged stabilization.

3.2. Loading of LLT. A series of absorption experiments was conducted to explore the loading capacity of the LLT. Figure 2 illustrates the absorption profiles of SEDDS into the LLT as a function of exposure time and the compression force. As shown in Figure 1, application of higher compression force during tablet compression increased the loading time and reduced the maximum theoretical loading amount. The loading process can be seen as the replacement of air in the tablet pores by liquid. It is consistent with the Washburn equation [23]: $v=r^{2} / 8 \mu_{\mathrm{eff}} * p_{c} / d$ where $v$ is the velocity of the interface between air and liquid, $r$ is the radius and $d$ the length of a pore, $p_{c}$ the capillary pressure and $\mu_{\text {eff }}$ is the effective viscosity. According to the equation, the capillary flow in the loading process is controlled mainly by capillary action. The fast absorption is caused by capillary suction and is determined by both the pore size distribution of LLT, the nature of the liquid viscosity and liquid-solid contact angle [16]. The higher compression pressure applied would cause the formation of smaller pore size distribution [18]. It may explain why the loading time increases at higher compression pressures and why the LLT subjected to higher compression pressure absorbed lower theoretical amount of SEDDS.

3.3. Characterization of CIO-Loaded Tablet. Table 2 shows the results of tests performed to evaluate the physical properties of the CIO-loaded tablet according to Chinese Pharmacopoeia (2010). It is clear that CIO-loaded tablet complied 
TABLE 2: Characteristics of the CIO-loaded tablet.

\begin{tabular}{lc}
\hline & CIO-loaded tablet \\
\hline Average CIO contents $(\% \pm \mathrm{SD})$ & $96.11 \pm 1.5$ \\
Friability $(\% \pm \mathrm{SD})$ & $0.60 \pm 0.18$ \\
Hardness $(\mathrm{N} \pm \mathrm{SD})$ & $30.1 \pm 7.00$ \\
Disintegration time $(\mathrm{min} \pm \mathrm{SD})$ & $0.31 \pm 0.20$ \\
Weight variation $(\mathrm{mg})$ & $1.55 \pm 0.022$ \\
\hline
\end{tabular}

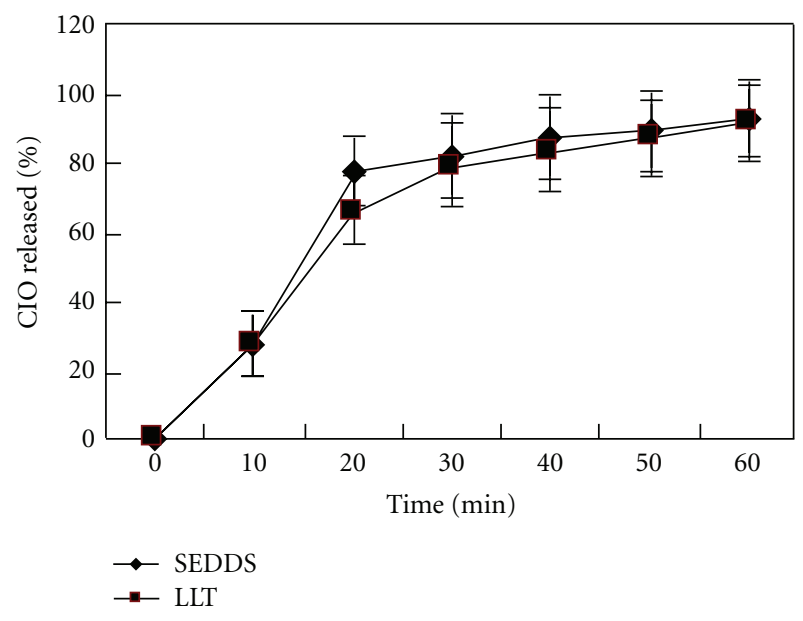

FIGURE 2: Drug release profiles of the SEDDS and LLT.

with the required specifications and standard regarding drug content uniformity. CIO-loaded tablet complied with Chinese Pharmacopeia friability test as the friability was less than $1 \%$ and there were no broken tablets. For the disintegration time results, CIO-loaded tablet showed very short disintegration time $(0.31 \pm 0.20$ seconds). Also, the CIO-loaded tablet passed the Chinese Pharmacopeia weight variation test.

3.4. In Vitro Drug Release Study. Drug release rate and the cumulative percent of CIO dissolved into the aqueous medium are important criteria that govern the quality of the LLT. The physical properties of the ingredients used to prepare the LLT have a profound effect on the CIO release rate. Drug release profiles of the CIO-tablet and CIO-SEDDS are shown in Figure 2. The CIO dissolution from both SEDDS and LLT formulations took place immediately. The fast drug release of the LLT may be explained by both an increase in the specific surface area of the drug resulting from the adsorption to the highly MAS porous spherical particles and possibly an amorphous state of the drug. The solid carrier, MAS, used in the LLT did not interfere the dissolution of CIO from the SEDDS. The results of the release profile suggested that the LLT preserved the enhancement of in vitro dissolution of $\mathrm{CIO}$ and would eventually enhance the dissolution of drug in vivo.

3.5. Pharmacokinetics of CIO-Loaded Tablet. Figure 3 shows plasma concentration-time curves of CIO after administration of three different formulations. The calculated pharmacokinetic parameters are summarized in Table 3. After
TABLe 3: Pharmacokinetic parameters after oral administration of CIO, CIO-LS, and CIO-LLT to rats.

\begin{tabular}{lcccc}
\hline Groups & $\begin{array}{c}\mathrm{AUC}_{0 \rightarrow 24 \mathrm{~h}} \\
(\mu \mathrm{g} \mathrm{h} / \mathrm{mL})\end{array}$ & $\begin{array}{c}C_{\max } \\
(\mu \mathrm{g} / \mathrm{mL})\end{array}$ & $T_{\max }(\mathrm{h})$ & $F(\%)$ \\
\hline CIO-LS & 1.96 & $0.51 \pm 0.30$ & $0.15 \pm 0.09$ & 2.5 \\
CIO-LLT & 1.68 & $0.43 \pm 0.21$ & $0.18 \pm 0.12$ & 2.2 \\
CIO & $\mathrm{NA}$ & $\mathrm{NA}$ & $\mathrm{NA}$ & 0 \\
\hline
\end{tabular}

Values are shown as means $\pm \mathrm{SD} .{ }^{*} P<0.0001$, NA: Not applicable. $(n=6)$,

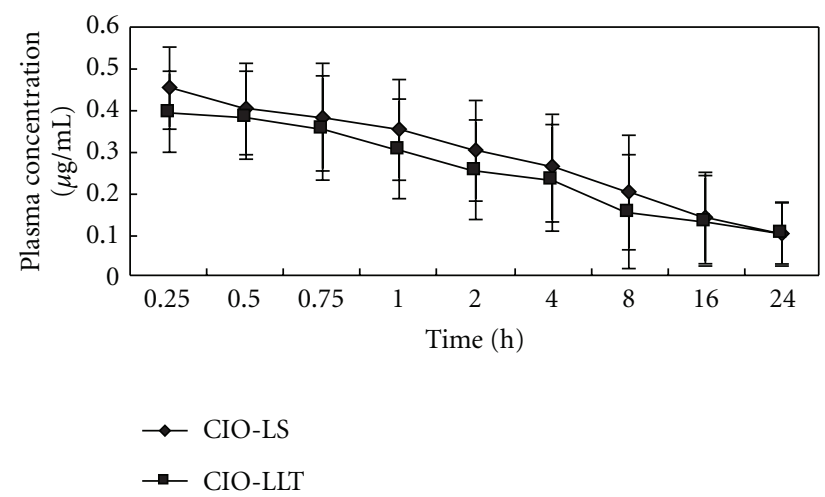

Figure 3: Mean whole blood concentrations of CIO in rats following oral doses of $100 \mathrm{mg}$ in the form of CIO-SEDDS and CIO- LLT. The total plasma concentrations of drug after oral administration of CIO could not be detected.

orally administration, only the plasma concentration-time profile and pharmacokinetic parameters of SEDDS and LLT could be obtained at the dose of $100 \mathrm{mg} / \mathrm{kg}$. The data of $\mathrm{CIO}$ were not meaningful because plasma levels of $\mathrm{CIO}$ were either below detectable limit and they were not high enough for accurate pharmacokinetic analysis. In the case of SEDDS (CI-LS), CIO was rapidly absorbed $\left(T_{\max }, 0.15 \pm 0.09 \mathrm{~h}\right)$ reaching a $C_{\max }$ of $0.51 \pm 0.30 \mu \mathrm{g} / \mathrm{mL}$. In the case of LLT (CIO-LLT), CIO was absorbed ( $T_{\max }, 0.18 \pm 0.12 \mathrm{~h}$ ) reaching a $C_{\max }$ of $0.43 \pm 0.21 \mu \mathrm{g} / \mathrm{mL}$. The bioavailability of CIO from each of the 3 formulations, estimated as the area under the whole blood curve was $0,2.5 \%$ and $2.2 \%$, respectively. It was compared using two-tailed Student's $t$-test. It did not show any statistically significant differences between the CIO-LS and CIO-LLT.

A significant increase $(P<0.0001)$ in the $C_{\max }$, AUC and $F$ were observed in the CIO-LLT group when compared with the CIO group. Thus, the higher plasma concentrations of CIO in LLT were contributed by improving the solubility of drug by SEDDS.

3.6. Effects of CIO-LLT on Glycaemic Metabolism. Alloxan is the most prominent diabetogenic chemicals in diabetes research. It is toxic glucose analogues that preferentially accumulate in pancreatic beta cells via the GLUT2 glucose transporter $[24,25]$. Alloxan has two distinct pathological effects: it selectively inhibits glucose-induced insulin secretion through specific inhibition of glucokinase, the glucose sensor of the beta cell, and it causes a state of insulindependent diabetes by selective necrosis of beta cells in type 1 


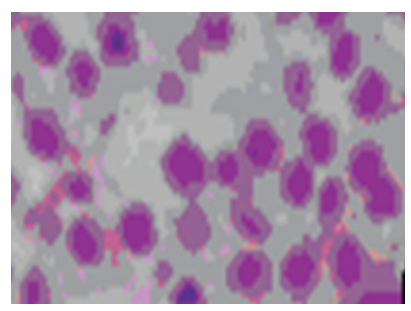

(a)

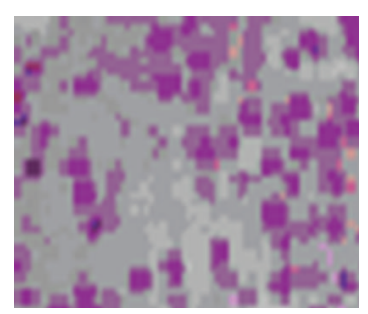

(b)

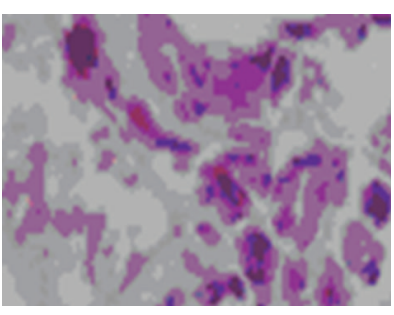

(c)

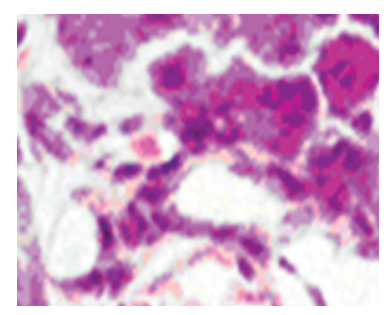

(d)

FIgURE 4: Islet cell death and replication represented by hematoxylin-eosin.

TABLE 4: Effect of CIO, CIO-LS and CIO-LLT on blood glucose and HbA1c levels in alloxan-hyperglycemic rats.

\begin{tabular}{lcc}
\hline Different groups & Blood glucose $(\mathrm{mmol} / \mathrm{L})$ & HbAlc \\
\hline Control group & $21.2 \pm 2.1$ & $11.8 \pm 0.23$ \\
CIO-LS-treated & $10.4 \pm 3.0^{*}$ & $7.0 \pm 0.31^{* *}$ \\
CIO-LLT-treated & $12.5 \pm 2.1^{*}$ & $7.9 \pm 0.20^{* *}$ \\
CIO-treated & $19.9 \pm 2.7$ & $11.0 \pm 0.20$ \\
\hline
\end{tabular}

Values are means \pm SEM, $n=10 .{ }^{*} P<0.05,{ }^{* *} P<0.01$ versus Control group.

TABLE 5: Effect of CIO, CIO-LS and CIO-LLT on serum insulin and hepatic glycogen level in alloxan-induced diabetic rats.

\begin{tabular}{lcc}
\hline Different groups & Serum insulin $(\mu \mathrm{U} / \mathrm{mL})$ & $\begin{array}{c}\text { Hepatic glycogen } \\
(\mathrm{mg} / \mathrm{g} \text { tissue })\end{array}$ \\
\hline Control group & $3.9 \pm 1.4$ & $13.3 \pm 3.6$ \\
CIO-LS-treated & $8.9 \pm 0.7^{* *}$ & $17.6 \pm 0.5^{*}$ \\
CIO-LLT-treated & $6.8 \pm 0.5^{* *}$ & $16.8 \pm 0.6^{*}$ \\
CIO-treated & $4.3 \pm 0.4$ & $13.8 \pm 0.5$ \\
\hline
\end{tabular}

Values are means \pm SEM, $n=10 .{ }^{*} P<0.05,{ }^{*} P<0.01$ versus Control group.

and type 2 diabetes mellitus [24,25]. So alloxan is the agent of choice for induction of diabetic experimental animals in this study.

The results of blood glucose from hyperglycemic rats induced by alloxan are presented in Table 4 . The levels of blood glucose decreased after administration of CIO-LS and CIO-LLT $(P<0.05)$. CIO-LS and CIO-LLT could decrease the concentration of HbAlc in plasma of alloxan-induced hyperglycemic group 45 days later $(P<0.01)$, as shown in Table 4 . However the same result did not occur in the CIO group.

The mechanisms of the hypoglycaemic effect of CIOLS and CIO-LLT have been also studied in this paper. As shown in Table 5, the levels of serum insulin elevated after administration of CIO-LS and CIO-LLT. However, the same results did not occur in the saline treated group $(3.8 \pm$ $0.4 \mu \mathrm{U} / \mathrm{mL}$ ) throughout the total duration of the study. It is possible that CIO bring about release of insulin from the surviving $\beta$-cells, as well from the recovered $\beta$-cells by CIO. The $\beta$-cells of the rats fed with CIO-LS and CIO-LLT were partly recovered (Figures $4(\mathrm{a})$ and $4(\mathrm{~b})$ ). $\beta$-Cells death and alteration of islet cell population were prominent in the diabetic rats that fed with $\mathrm{CIO}$ (Figure 4(c)) and saline (Figure 4(d)).

Glycogen storage in the liver is another way to maintain blood glucose concentration in mammals. Decreased hepatic glucose production is induced by glycogen synthesis. CIOLS and CIO-LLT produced the increase in the level of hepatic glycogen. Concentrations of hepatic glycogen were lower in saline-treated rats than CIO-treated rats (Table 5). However, there is no significant difference between them $(P>0.05)$.

\section{Conclusion}

The work presented in this paper focuses on the ability of LLT prepared from MAS to be loaded with a SEDDS system containing CIO. It combines the advantages of SEDDS (high solubility and bioavailability) with those of solid dosage forms (high stability). CIO-loaded tablet could improve the glycaemic metabolism of CIO. It was contributed by improving the bioavailability drug by SEDDS.

\section{Acknowledgments}

This project was supported by Project of Shandong Province Higher Educational Science and Technology Program (J08LH62). Han, as the author of the manuscript, have or do not have a direct financial relation with the commercial identity mentioned in our paper that might lead to a conflict of interest for any of the authors.

\section{References}

[1] H. King, R. E. Aubert, and W. H. Herman, "Global burden of diabetes, 1995-2025: prevalence, numerical estimates, and projections," Diabetes Care, vol. 21, no. 9, pp. 1414-1431, 1998.

[2] S. H. Kim, S. H. Hyun, and S. Y. Choung, "Anti-diabetic effect of cinnamon extract on blood glucose in $\mathrm{db} / \mathrm{db}$ mice," Journal of Ethnopharmacology, vol. 104, no. 1-2, pp. 119-123, 2006.

[3] E. Ernst, "Plants with hypoglycemic activity in humans," Phytomedicine, vol. 4, no. 1, pp. 73-78, 1997.

[4] J. Gruenwald, J. Freder, and N. Armbruester, "Cinnamon and health," Critical Reviews in Food Science and Nutrition, vol. 50, no. 9, pp. 822-834, 2010.

[5] M. Modak, P. Dixit, J. Londhe, S. Ghaskadbi, and T. P. A. Devasagayam, "Indian herbs and herbal drugs used for the treatment of diabetes," Journal of Clinical Biochemistry and Nutrition, vol. 40, no. 3, pp. 163-173, 2007. 
[6] L.-P. Ruan, B.-Y. Yu, G.-M. Fu, and D.-N. Zhu, "Improving the solubility of ampelopsin by solid dispersions and inclusion complexes," Journal of Pharmaceutical and Biomedical Analysis, vol. 38, no. 3, pp. 457-464, 2005.

[7] T. Gershanik, S. Benzeno, and S. Benita, "Interaction of the SELDDS with mucosa of everted rat intestine as a function of surface charge and particle size," Pharmaceutical Research, vol. 15, pp. 863-869, 1998.

[8] S. Nazzal, N. Guven, I. K. Reddy, and M. A. Khan, "Preparation and characterization of Coenzyme Q10-Eudragit ${ }^{\circledR}$ solid dispersion," Drug Development and Industrial Pharmacy, vol. 28, no. 1, pp. 49-57, 2002.

[9] S. A. Charman, W. N. Charman, M. C. Rogge, T. D. Wilson, F. J. Dutko, and C. W. Pouton, "Self-emulsifying drug delivery systems: formulation and biopharmaceutic evaluation of an investigational lipophilic compound," Pharmaceutical Research, vol. 9, no. 1, pp. 87-93, 1992.

[10] C. Tuleu, M. Newton, J. Rose et al., "Comparative bioavailability study in dogs of self-emulsifying formulation of progesterone presented in a pellet and liquid form compared with an aqueous suspension of progesterone," Journal of Pharmaceutical Sciences, vol. 93, no. 6, pp. 1495-1502, 2004.

[11] S. M. Khoo, A. J. Humberstone, C. J. H. Porter, G. A. Edwards, and W. N. Charman, "Formulation design and bioavailability assessment of lipidic self- emulsifying formulations of halofantrine," International Journal of Pharmaceutics, vol. 167, no. 1-2, pp. 155-164, 1998.

[12] T. Yi, J. Wan, H. Xu, and X. Yang, "A new solid self-microemulsifying formulation prepared by spray-drying to improve the oral bioavailability of poorly water soluble drugs," European Journal of Pharmaceutics and Biopharmaceutics, vol. 70, no. 2, pp. 439-444, 2008.

[13] R. P. Dixit and M. S. Nagarsenker, "Self-nanoemulsifying granules of ezetimibe: design, optimization and evaluation," European Journal of Pharmaceutical Sciences, vol. 35, no. 3, pp. 183192, 2008.

[14] S. Nazzal, M. Nutan, A. Palamakula, R. Shah, A. A. Zaghloul, and M. A. Khan, "Optimization of a self-nanoemulsified tablet dosage form of Ubiquinone using response surface methodology: effect of formulation ingredients," International Journal of Pharmaceutics, vol. 240, no. 1-2, pp. 103-114, 2002.

[15] V. Jannin, J. Musakhanian, and D. Marchaud, "Approaches for the development of solid and semi-solid lipid-based formulations," Advanced Drug Delivery Reviews, vol. 60, no. 6, pp. 734-746, 2008.

[16] T. Ruhland, S. D. Nielsen, P. Holm, and C. H. Christensen, "Nanoporous magnesium aluminometasilicate tablets for precise, controlled, and continuous dosing of chemical reagents and catalysts: applications in parallel solution-phase synthesis," Journal of Combinatorial Chemistry, vol. 9, no. 2, pp. 301305, 2007.

[17] J. Xi, Q. Chang, C. K. Chan et al., "Formulation development and bioavailability evaluation of a self-nanoemulsified drug delivery system of oleanolic acid," AAPS PharmSciTech, vol. 10, no. 1, pp. 172-182, 2009.

[18] C. Sander and P. Holm, "Porous magnesium aluminometasilicate tablets as carrier of a cyclosporine self-emulsifying formulation," AAPS PharmSciTech, vol. 10, no. 4, pp. 1388-1395, 2009.

[19] J. H. Yoo, S. Shanmugam, P. Thapa et al., "Novel self-nanoemulsifying drug delivery system for enhanced solubility and dissolution of lutein," Archives of Pharmacal Research, vol. 33, no. 3, pp. 417-426, 2010.
[20] P. Balakrishnan, B. J. Lee, D. H. Oh et al., "Enhanced oral bioavailability of dexibuprofen by a novel solid Self-emulsifying drug delivery system (SEDDS)," European Journal of Pharmaceutics and Biopharmaceutics, vol. 72, no. 3, pp. 539545, 2009.

[21] T. Gershanik, E. Haltner, C. M. Lehr, and S. Benita, "Chargedependent interaction of self-emulsifying oil formulations with Caco-2 cells monolayers: binding, effects on barrier function and cytotoxicity," International Journal of Pharmaceutics, vol. 211, no. 1-2, pp. 29-36, 2000.

[22] L. L. Wei, P. N. Sun, S. F. Nie, and W. S. Pan, "Preparation and evaluation of SEDDS and SMEDDS containing carvedilol," Drug Development and Industrial Pharmacy, vol. 31, no. 8, pp. 785-794, 2005.

[23] E. W. Washburn, “The dynamics of capillary flow," Physical Review, vol. 17, no. 3, pp. 273-283, 1921.

[24] F. K. Gorus, W. J. Malaisse, and D. G. Pipeleers, "Selective uptake of alloxan by pancreatic B-cells," Biochemical Journal, vol. 208, no. 2, pp. 513-515, 1982.

[25] M. Elsner, M. Tiedge, B. Guldbakke, R. Munday, and S. Lenzen, "Importance of the GLUT2 glucose transporter for pancreatic beta cell toxicity of alloxan," Diabetologia, vol. 45, no. 11, pp. 1542-1549, 2002. 

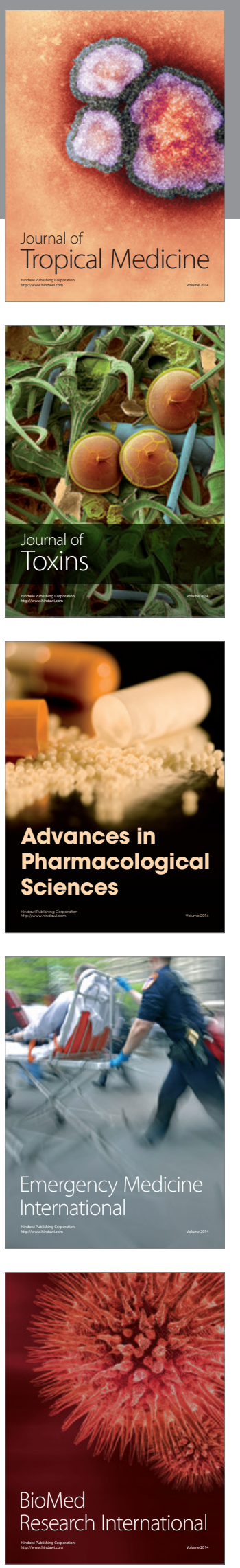
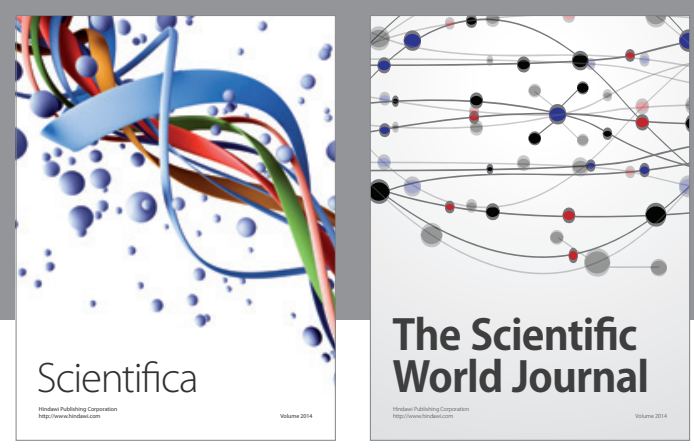

The Scientific World Journal
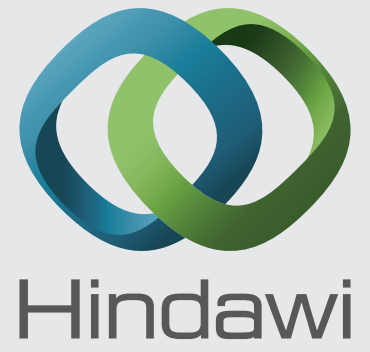

Submit your manuscripts at

http://www.hindawi.com
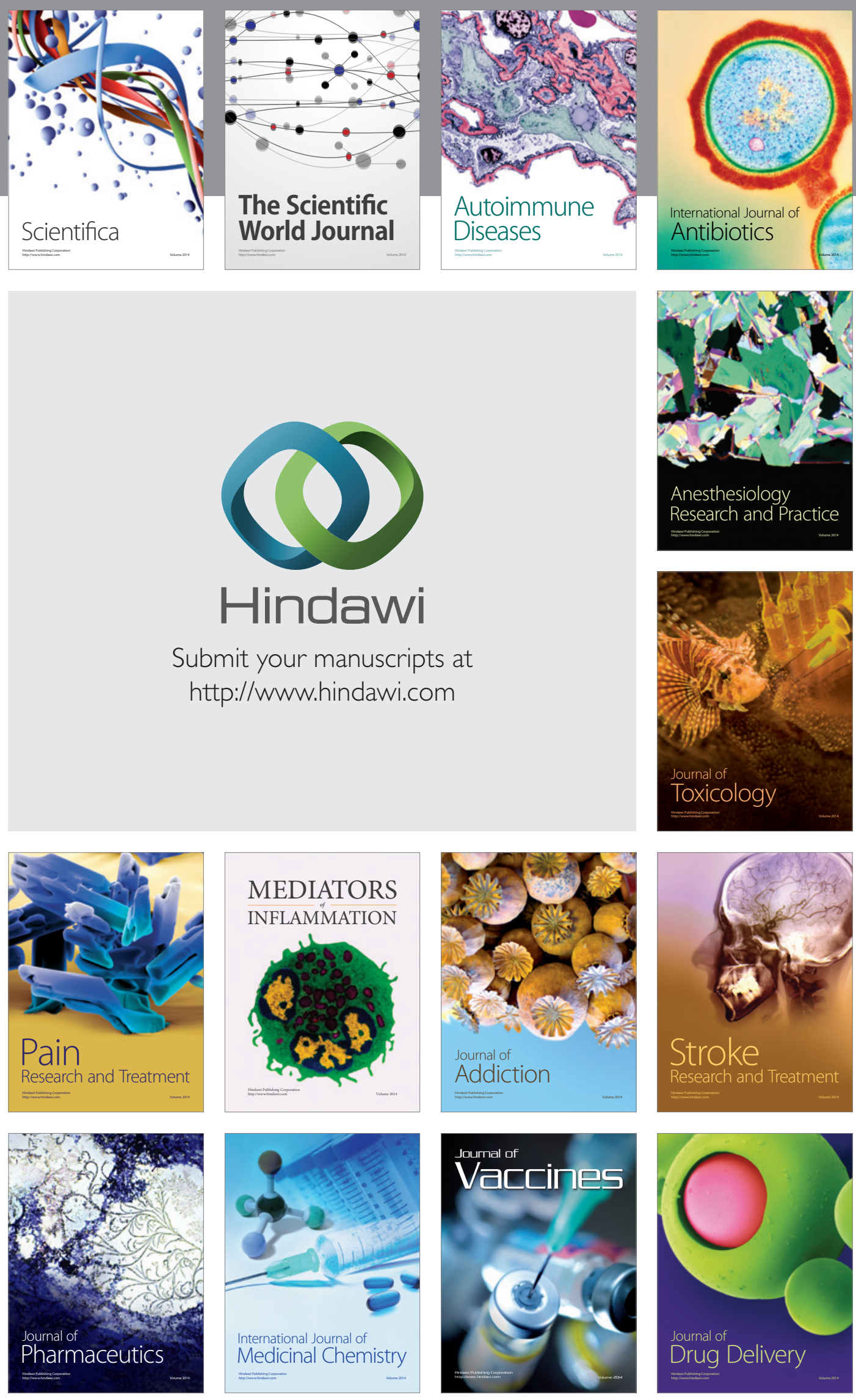